\title{
Dislexia Específica de Evolução
}

\author{
Specific of Evolution Dyslexy
}

Josefina Elvira Novaes Rêgo de Araújo ${ }^{1}$ Fábio Aguiar Alves ${ }^{2}$

\section{Resumo}

A dificuldade de entender o que está escrito sob seus olhos e a de escrever o que está pensando claramente são problemas do disléxico. Receber a informação através da leitura se torna impossível, ou completamente, ou em grau maior ou menor. O disléxico pode não entender a mensagem ou entendê-la mal, inferindo um sentido deturpado. Por outro lado, pode não conseguir colocar no papel seu pensamento, ou chegar a fazê-lo de forma tão incorreta quanto a escrita das palavras, se tornando impossível o entendimento do assunto. O disléxico, muitas vezes, pode ser mais inteligente do que a média dos estudantes e fica a margem do seu meio a partir do momento em que entra para a escola, quando seu problema aparece. Acredita-se haver pelo menos dez disléxicos entre cada cem indivíduos, por isso é tão urgente que saibamos sobre o assunto. Há um tratamento que pode ajudá-los a vencer suas dificuldades, e sob o ponto de vista prático, a passarem para o grupo de seus iguais, utilizando-se razoavelmente da leitura e da escrita.

Palavras-chave: Dislexia, Inclusão Social.

\section{Abstract}

The difficulty of understanding what is written under the eyes and of writing what is in mind clearly is the problem of dyslexic. Receiving information through reading becomes impossible, completely or in bigger or smaller grades. Dyslexic cannot understand the message of understand it badly, inferring a modified meaning. Yet, helshe cannot put on paper his/her thoughts, or puts on paper but in such incorrect way of words graph that it is impossible the comprehension of the subject. Dyslexic many times can be more intelligent than the average of students and helshe stays apart from his/ her environment from the moment helshe goes to school and his/her problem appears. It is believed that there are at least ten dyslexics among a hundred individuals, that is why is so urgent that we know about this subject. There is a treatment which can help dyslexics to overcome their diffculties and, in a practical point of view, to go to the equals group, using reasonably reading and writing.

Keywords: Dislexy, Social Inclusion

\footnotetext{
${ }^{1}$ Mestranda - Mestrado Profissional em Ensino em Ciências da Saúde e do Meio Ambiente - UniFOA

${ }^{2}$ Doutor - Mestrado Profissional em Ensino em Ciências da Saúde e do Meio Ambiente - UniFOA
} 


\section{INTRODUÇÁO}

Existe um grupo entre os indivíduos que lêem mal, isso independe de problemas emocionais, intelectuais, educacionais ou lingüísticos. É incompreensível que uma pessoa de inteligência normal náo leia ou escreva com facilidade. A dificuldade de entender o que está escrito e a de escrever claramente o que está pensando é o que chamamos de dislexia específica de evolução.

As crianças portadoras desse distúrbio sofrem com o desconhecimento dos educadores e pais, sendo discriminadas no seu percurso escolar. Informar este problema ao maior número de pessoas envolvidas na educação destas crianças e possibilitar um caminho para amenizar os seus problemas, é a intenção deste trabalho.

Dislexia, do grego dys, mal e lexis, palavra ou frase. Em sentido amplo, qualquer dificuldade que se verifique no aprendizado da leitura e da escrita, não importando qual sua causa. Em sentido estrito, o termo designa somente dificuldade da leitura e escrita, em indivíduos sem outros problemas de aprendizagem, e sem déficit sensorial ou de adaptação. Essas dificuldades são independentes do método de alfabetização empregado, embora se evidencie mais em se tratando do método global.

Os franceses dizem dislexia específica de evolução. Evolução porque os sintomas tendem, com o tempo, desaparecer espontaneamente, e específica porque se limitam ao campo da leitura e escrita.

\section{QUADRO ESCOLAR.}

No início do ensino fundamental, o disléxico pode tem bom desempenho em disciplinas como matemática, conhecimentos gerais, excetuando leitura e linguagem, termo que usamos para designar o conjunto de redaçóes, cópias e ditados, havendo discrepância nas notas. Mais tarde, a dificuldade em matemática poderá aumentar devido a leitura e compreensão dos enunciados de problemas e, conseqüentemente, com o prejuízo do raciocínio e resolução dos mesmos. Pode haver dificuldade na escrita de algarismos, que podem aparecer invertidos principalmente se forem de números grandes. Contudo, o prejuízo dos cálculos escritos não é acompanhado de deficiência dos cálculos mentais. Dificuldades de noção de espaço podem prejudicar o aprendizado de geografia ou geometria.

O aprendizado da leitura e escrita do disléxico apresenta dificuldade de grau variável, às vezes insuperável pelos métodos comuns do ensino necessitando de métodos alternativos. Geralmente podem chegar a reconhecer as letras e a leitura, porém a escrita de uma sílaba qualquer, pode persistir impraticável.

\subsection{Tipos de Erros na Leitura e Escrita}

- Confusão entre letras simétricas: p, q, m, n, b, g, q.

- Confusão entre letras de formas vizinhas: j, g, - m, n (gegum por jejum, nas por mas, moite por noite).

- Confusão com letras foneticamente semelhantes: $t, d$, - p, b.- g, c , (turante por durante)

- Inversão de ordem de letras na sílaba: pal por pla.

- Inversão da ordem das sílabas numa palavra como: areoplano por aeroplano, Camer por Carmem.

- Leitura e escrita em espelho.

- Substituiçáo de uma palavra por outra de significado aproximado : soltou o ratinho por salvou o ratinho.

- Omissão de letras, sílabas ou palavras: giado por guiado - entrando por encontrando.

- Repetiçóes de palavras: alfabeto alfabeto é...

- Adição de letras, sílabas ou palavras: fiaque por fique.

- Substituição de uma letra por outra.

- Omissão de uma palavra numa frase, quando a ignora, ou não tenta ler ou exita demais na leitura dela.

\subsection{Tipo de Leitura}

A leitura do disléxico é, em geral, má, independente dos erros de que falamos. Costuma fazer sílaba por sílaba de modo hesitante, exigindo muita atenção e um esforço que nem sempre é levado em consideração. Lê monótona e lentamente, característica importante. Às vezes, há dificuldade na passagem do final de uma linha para a seguinte. A pontuação pode não ser respeitada e o disléxico só lê da direita para a esquerda ( leitura em espelho ).

A leitura silenciosa é impossível, fazendo-se de modo subvocal, isto é, murmurante ou acompanhado de movimento de lábios ou glote.

\subsection{Compreensão da Leitura}

Apresentam dificuldade de compreensão do que lêem, o que pode ser devido ao esforço despendido em muitas palavras, mas que pode acontecer também, mesmo que tenha havido uma leitura correta.

\subsection{Tipo de Escrita}

As dificuldades geralmente são grandes ao ditado e à redação espontânea, podendo mesmo ser extremas, neste caso, uma ortografia, as palavras não são reconhecidas e as frases ilegíveis. Costumam ser menores nas cópias, podendo 
passar sem muita dificuldade da letra de forma para uma letra de mão. Há disléxicos que são capazes de escrever por ditado, embora não dominem a escrita espontânea.

\subsection{A Disortografia}

Pode ser o único achado de exame em caso de dislexia leve, não tendo sido descoberta logo no início da alfabetização, as dificuldades na leitura podem ter desaparecido, ficando os erros de escrita.

\subsection{Disturbios Associados}

Nos disléxicos, não se encontram, ao exame neurológico, mais do que sinais menores, cujo achado se pode verificar normalmente em crianças, sendo que vão desaparecendo à medida que elas crescem. Não são obrigatórios na dislexia, mas podem ser importantes quando presentes.

A dislexia é sempre acompanhada de desorientação quanto à direita e esquerda. $\mathrm{Na}$ literatura francesa especializada, os sinais neurológicos menores e os distúrbios de lateralidade são qualificados como instrumentais, ( o termo " instrumento" designando certo grau de desenvolvimento da fala, da estruturação espacial, da lateralização, da personalidade, e outros que são pré requisitos para aprendizagem da leitura e escrita ).

\subsection{Distúrbios da Fala e da Linguagem}

O disléxico pode, às vezes, apresentar retardo no desenvolvimento da linguagem e dificuldade na articulação das palavras. A dislexia pode, às vezes, vir acompanhada de gagueira . Pode-se ainda verificar inversóes de conceitos ( preto por branco ), pobreza de vocabulário e imaturidade ou inadequação da sintaxe. Encontra-se freqüente ocorrência de afasia expressiva e receptiva, sendo a primeira evidenciada, principalmente, por erro no emprego de palavras ( parafrasia ). Existe também dificuldade em recordar nome de pessoas ou objetos, e com necessidade de descrever com gestos ( afasia nominal ), alteração da ordem das palavras, uso de palavras ou frases sem sentido no contexto, incapacidade de responder perguntas feitas abruptamente ou cumprir ordens imediatamente.

\subsection{Distúrbios na Noçáo de Espaço- do Esquema Corporal e do Sentido de Direçáo}

Estes indivíduos podem apresentar confusão quanto às coordenadas diversas de espaço: em cima, embaixo, vertical oblíqua; ou em relaçáo a movimentos horário e anti- horário. Freqüentemente, essas pessoas não conseguem uma disposição correta das palavras no papel, como já vimos, nem sempre conseguindo armar contas corretamente, ler números, apresentando dificuldade em armar quebra cabeça.

Quanto ao esquema corporal, podem não saber localizar partes do corpo ou confundi-las, ou ainda, demonstrar falhas ao desenhar a figura humana. Tem dificuldade no vestir-se, dar nó no sapato ou jogar bola. $\mathrm{O}$ sentido de direção é comprometido, devido às confusôes entre direita e esquerda. Podem os disléxicos ser incapazes de dirigir um carro, seguir orientação dos outros, encontrarem o caminho de volta.

\subsection{Distúrbios da Noção de Tempo - Da Percepçáo do Ritmo}

Os distúrbios da noção do tempo estão estreitamente ligados aos de noção do espaço, sendo tratados, às vezes, em conjunto como distúrbio têmporo-espacial. Esses distúrbios Referem-se aos problemas de seqüências, no que dizem respeito a espaço e tempo concomitantemente. Assim, um indivíduo pode repetir uma sílaba como cra, e em seguida escreve-la car, errando a seqüência gráfica (espaço), por não ter percebido que o som do r vem após o correspondente ao c e antes do a (tempo).

\subsection{Aspectos Oftalmológicos}

Em alguns casos o predomínio do olho esquerdo levaria os olhos da direita para esquerda durante a leitura, trazendo prejuízo à compreensão do material lido.

\subsection{Fatores Auditivos}

Os disléxicos mostram deficiência no relacionamento de estímulos visuais com estímulos auditivos verbais, enquanto o relacionamento de estímulos visuais com estímulos auditivos não verbais se processa normalmente. $\mathrm{O}$ defeito essencial parece consistir em que formas e sons não chegam a alcançar significado. $\mathrm{O}$ disléxico não integra sons isolados, embora conhecidos, a fim de, com eles, formar palavra; podem náo conseguir ler uma palavra apesar de conhecer todas as letras que a compóe. Apesar disso, os autores não se referem a exames otorrinolaringológicos em relação aos disléxicos

\subsection{Dados Psiquiátricos}

Não está relacionada com défcit de inteligência, 
embora possa haver concomitância dos dois quadros. Parece ser mais freqüente em indivíduos de inteligência superior.

\subsection{Noçóes Relativas à Genética}

Notou-se pouco depois de isolado o quadro, que a dislexia podia incidir em mais de uma pessoa na família.

\section{CONCLUSÁO}

A dislexia não é uma doença e sim uma dificuldade específica no aprendizado da leitura e escrita. Seus sintomas podem surgir na pré-escola e jamais desaparecer apesar de poder vir a ter um desenvolvimento normal ou até acima da média. Os métodos convencionais para alfabetizá-lo dificilmente terão sucesso, sendo necessário a busca de um caminho alternativo. A escola deve estar preparada para atender esse aluno.

O diagnóstico da dislexia é feito por uma equipe multidisciplinar, com psicopedagogo, psicólogo, neurologista e fonoaudiólogo.

O conhecimento de educadores sobre a dislexia é necessário para o seu reconhecimento e atendimento levando estes alunos a inclusão em seu meio escolar e social.

\section{REFERÊNCIAS}

BAUER, James J. Dislexia: ultrapassando as barreiras do preconceito. Sáo Paulo: Casa do Psicólogo, 1997.

CUBA dos Santos, Cacilda. Dislexia Específica de Evoluçáo. 2 ed. São Paulo: Sarvier, 1986.

RICHARDSON, Sylvia. Dislexia a dificuldade oculta, Revista Insight-Psicoterapia. São Paulo, n 84, maio ,1988, ano Vll, p. 04 a 07.

ESTILL, Clélia Argolo. Como entender a criança com dislexia. O Globo , Rio de Janeiro. Jornal da Família ,04 de julho, 1999.

FERREIRA, Suzane. Carta de uma mãe. Informativo ABD. São Paulo, n 43, janeiro a março, 1999.

BAUER, James J. Dislexia: ultrapassando as barreiras do preconceito.São Paulo: Casa do Psicólogo,1997.

NOVAES, Maria Helena. Psicologia Escolar. 2 ed. Rio de Janeiro. Vozes, 1972.
PACCINI, Maria Julia. Cartilha para reeducaçáo de Disléxicos. Presidente Prudente: Impress, 2002.

HOUT, Anne Van, Sestienne,Fraçoise. Dislexias, Descriçáo, Avaliação, Explicaçáo e Tratamento.2 ed. Tradução de Claudia Schilling. Porto Alegre: Artes Médicas,2002.

MARTINS, Vicente. Lingüística Aplicada às Dificuldades de Aprendizagem Relacionadas com a Linguagem. 2002. Disponível na Internet. http/sites.uol.com.br/ Vicente Martins.
Endereço para Correspondência:

Josefina Elvira Novaes Rêgo de Araújo jo.elvira@gmail.com Mestrado Profissional em Ensino em Ciências da Saúde e do Meio Ambiente

Centro Universitário de Volta Redonda Campus Três Poços Av. Paulo Erlei Alves Abrantes, no 1325 , Três Poços - Volta Redonda / RJ CEP: 27240-560 